\title{
Brucine suppresses ethanol intake and preference in alcohol-preferring Fawn-Hooded rats
}

\author{
Yu-ling $\mathrm{LI}^{1}$, Qing LIU $^{1}$, Qi GONG ${ }^{1}$, Jun-xu $\mathrm{LI}^{2}$, Shou-peng WEI ${ }^{1}$, Yan-ting WANG ${ }^{1}$, Hui LIANG ${ }^{1}$, Min ZHANG ${ }^{1}$, Li JING ${ }^{2}$, Zheng \\ YONG $^{3}$, Andrew J LAWRENCE ${ }^{4, *}$, Jian-hui LIANG ${ }^{1, *}$ \\ ${ }^{1}$ National Institute on Drug Dependence, Peking University, Beijing 100191, China; ${ }^{2}$ Department of Pharmacology and Toxicology, \\ School of Medicine and Biomedical Sciences, University at Buffalo, State University of New York, Buffalo, NY 14214, USA; ${ }^{3}$ Institute \\ of Pharmacology \& Toxicology, Academy of Military Medical Sciences, Beijing 100850, China; ${ }^{4}$ Florey Institute of Neuroscience and \\ Mental Health, University of Melbourne, Parkville, Victoria 3010, Australia
}

\begin{abstract}
Aim: Brucine (BRU) extracted from the seeds of Strychnos nux-vomica $L$ is glycine receptor antagonist. We hypothesize that BRU may modify alcohol consumption by acting at glycine receptors, and evaluated the pharmacodynamic profiles and adverse effects of BRU in rat models of alcohol abuse.

Methods: Alcohol-preferring Fawn-Hooded (FH/Wjd) rats were administered BRU (10, 20 or $30 \mathrm{mg} / \mathrm{kg}$, sc). The effects of BRU on alcohol consumption were examined in ethanol 2-bottle-choice drinking paradigm, ethanol/sucrose operant self-administration paradigm and 5-d ethanol deprivation test. In addition, open field test was used to assess the general locomotor activity of FH/Wjd rats, and conditioned place preference (CPP) was conducted to assess conditioned reinforcing effect.

Results: In ethanol 2-bottle-choice drinking paradigm, treatment with BRU for 10 consecutive days dose-dependently decreased the ethanol intake associated with a compensatory increase of water intake, but unchanged the daily total fluid intake and body weight. In ethanol/sucrose operant self-administration paradigms, BRU (30 mg/kg) administered before each testing session significantly decreased the number of lever presses for ethanol and the ethanol intake, without affecting the number of sucrose (10\%) responses, total sucrose intake, and the number of lever presses for water. Acute treatment with BRU (30 mg/kg) completely suppressed the deprivation-induced elevation of ethanol consumption. Treatment with BRU (10, 20, and $30 \mathrm{mg} / \mathrm{kg})$ did not alter locomotion of FH/Wjd rats, nor did it produce place preference or aversion.

Conclusion: BRU selectively decreases ethanol consumption with minimal adverse effects. Therefore, BRU may represent a new pharmacotherapy for alcoholism.
\end{abstract}

Keywords: alcoholism; ethanol; brucine; glycine receptor antagonist; Fawn-Hooded (FH/Wjd) rat

Acta Pharmacologica Sinica (2014) 35: 853-861; doi: 10.1038/aps.2014.28; published online 9 Jun 2014

\section{Introduction}

As a chronic psychiatric disorder, alcoholism imposes a significant medical and economic burden on both individuals and society ${ }^{[1,2]}$. Alcohol consumption is the world's third largest risk factor for disease and disability and is considered to cause epilepsy, liver cirrhosis, pancreatitis, angiocardiopathy and several types of cancer ${ }^{[3-6]}$. Currently, there are only three FDA-approved medications available for the treatment of alcohol dependence, disulfiram, naltrexone and acamprosate. They each have only limited effectiveness in select alcoholic

Part of the results have been published as meeting abstract in Acta Pharmacol Sin 2013; 34: s129 and Chin Pharmacol 2013; 13: 18-9.

* To whom correspondence should be addressed.

E-mail liangjh@bjmu.edu.cn (Jian-hui LIANG); andrew.lawrence@florey.edu.au (Andrew J LAWRENCE)

Received 2014-01-01 Accepted 2014-03-05 patients, and they also have significant adverse effects such as fatigue, abdominal pain, diarrhea, nausea, vomiting, blurred vision, depression and dizziness ${ }^{[7-10]}$. This lack of choice in medicine often impacts the effective treatment of alcohol abuse in clinical practice ${ }^{[1]}$. Thus, more effective pharmacotherapies for alcoholism are needed ${ }^{[11]}$.

Semen strychni, the dried seed of the Strychnos nux-vomica L, has been effectively used in traditional Chinese medicine for hundreds of years ${ }^{[12]}$. Alkaloids are believed to be the major active components in Semen strychni and are responsible for its pharmacological and toxic effects ${ }^{[13]}$. There are 16 alkaloids isolated and identified from the seed, of which $70 \%$ is strychnine and brucine ${ }^{[13]}$. Strychnine is the alkaloid present at the highest concentration in the Semen strychni. It shows analgesic, anti-inflammatory and anti-tumor activities in preclinical studies ${ }^{[14]}$. However, it is a poison to humans and 
most livestock. Brucine (BRU, Figure 1), an odorless white crystalline solid alkaloid (molecular weight, 394.45), is the second most abundant alkaloid in the Semen strychnine ${ }^{[15]}$. The $\mathrm{LD}_{50}$ values of strychnine and BRU in mice (ip) were reported to be 1.1 and $50.1 \mathrm{mg} / \mathrm{kg}$, respectively, which means that the toxicity of BRU is much lower than strychnine ${ }^{[13]}$. The existing literature suggests that BRU exerts the following pharmacological effects: cough suppressant, microcirculation facilitation, cell protection, pain relief, anti-rheumatic and anti-tumor effects $^{[12,16,17]}$. However, the effects of BRU on alcohol abuse have not been documented.

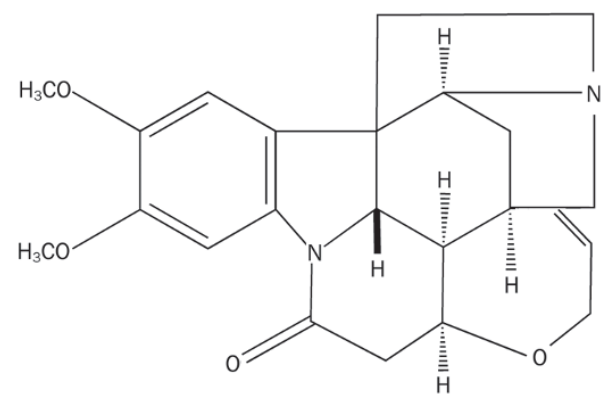

Figure 1. Chemical structure of brucine, a major alkaloid present in Strychnos nux-vomica seeds.

The central GABAergic and glycinergic systems are implicated in alcohol abuse and dependence ${ }^{[18]}$. In particular, the functions of a 1 or a 2 glycine receptors subtypes are enhanced by alcohol treatment ${ }^{[19]}$. Because BRU is an antagonist at the a1 and $\alpha 1 \beta$ glycine receptor subtypes ${ }^{[20]}$, we hypothesize that BRU may be able to modify alcohol consumption by acting at glycine receptors in alcohol-preferring Fawn-Hooded (FH/ Wjd) rats.

The goal of the current study was to examine the role of BRU in the modulation of ethanol consumption, ethanol seeking and deprivation-induced drinking in $\mathrm{FH} / \mathrm{Wjd}$ rats. The specificity of BRU on ethanol effects was compared to its effect on sucrose drinking. The effect of BRU on locomotion and the Pavlovian conditioning of BRU were also studied to provide preliminary safety pharmacological information for further BRU drug development.

\section{Materials and methods Animals}

The $\mathrm{FH} / \mathrm{Wjd}$ rats were obtained from the Florey Institute of Neuroscience and Mental Health, University of Melbourne (Melbourne, Vic, Australia) and bred at the Department of Laboratory Animal Sciences, Peking University Health Science Center. Adult male $\mathrm{FH} / \mathrm{Wjd}$ rats [Grade II, certificate number of the breeder: SCXK (Jing) 2011-0012], approximately 250-300 $\mathrm{g}$ at the start of the study, were individually housed and maintained with free access to food and water, except when stated otherwise (room temperature: $22 \pm 1^{\circ} \mathrm{C}$; relative humidity: $50 \% \pm 10 \%$ ). The animal facility was under a 12 -h light/dark cycle (lights on at 8:00 AM). The rats were habituated to the housing room and experimenter handling for one week before the experimental procedures. All studies were conducted in accordance with the NIH Guide for the Care and Use of Laboratory Animals (NIH Publications No 80-23, revised 1996) and approved by the Peking University Committee on Animal Care and Use.

\section{Drugs}

The BRU sulfate salt hydrate (Sigma-Aldrich, St Louis, MO, USA) was dissolved in $0.9 \%$ saline and injected subcutaneously at a volume of $1 \mathrm{~mL} / \mathrm{kg}$. The anhydrous ethanol and sucrose were purchased from Beijing Chemical Factory (Beijing, China) and prepared with tap water to various concentrations.

\section{Ethanol 2-bottle-choice drinking paradigm}

$\mathrm{FH} / \mathrm{Wjd}$ rats were trained to drink ethanol using classical methods with minor modifications ${ }^{[21]}$. The alcohol-preferring $\mathrm{FH} / \mathrm{Wjd}$ rats (ethanol preference $>65 \%$ ) were continuously (24 h per day) offered two bottles containing ethanol (5\% v/v, in tap water) or tap water for 8 consecutive weeks. The ethanol and water were monitored once daily by bottle weighing immediately before the onset of the dark phase. The bottles were refilled daily with fresh solution and their left-right positions interchanged randomly to exclude the development of position preference. Standard rat chow was always available. At the end of the 8-week period, the rats were randomly divided into 4 groups $(n=8)$ matched for similar daily ethanol consumption and preference over the last $7 \mathrm{~d}$. During the test, all rats were subcutaneously administered with saline twice daily (at 8:00 AM and 7:30 PM) for the first 3 consecutive days, then they were injected with saline or various doses $(10,20$, and $30 \mathrm{mg} / \mathrm{kg}$ ) of BRU for 10 consecutive days and their consumption of ethanol, water and food were measured for $24 \mathrm{~h}$. The ethanol concentration was selected on the basis of our previous studies, which showed that $\mathrm{FH} / \mathrm{Wjd}$ rats exhibited higher preference for $5 \%$ ethanol ${ }^{[22]}$. The drug doses were chosen based on a pilot study.

\section{Ethanol/sucrose self-administration procedure}

To test ethanol or sucrose oral self-administration in adult $\mathrm{FH} /$ Wjd rats, a custom-made WS-1 operant self-administration apparatus was employed ${ }^{[23]}$. The device was composed of 6 operant chambers $(29.5 \mathrm{~cm} \times 25.5 \mathrm{~cm} \times 25 \mathrm{~cm})$ housed in soundattenuating cubicles with an air-vent and house light. Levers $(3 \mathrm{~cm} \times 2.3 \mathrm{~cm})$ were installed on each side of the chamber, 5 $\mathrm{cm}$ above the floor. A stimulus light and buzzer were placed above the lever. Ethanol, sucrose or water $(0.03 \mathrm{~mL})$ was delivered from a $10 \mathrm{~mL}$ glass syringe connected to an automatic infusion pump. Pressing one of the two levers led to a 3-s combined tone and light cue. Fluid delivery and operant responses were recorded by a computer.

Before ethanol operant self-administration experiments, $\mathrm{FH} / \mathrm{Wjd}$ rats were given a $10 \%$ ethanol solution as the only liquid source for $4 \mathrm{~d}$. During the next 2 weeks, the rats had 
free access to $5 \%$ ethanol and tap water. At the end of the 14 th $\mathrm{d}$, the rats were limited to $30 \mathrm{~min}$ of water per day for two successive days. On the evening of the second day of water limitation, the rats were put into the operant chambers for a 12-h response session under a fixed ratio 1 (FR1) schedule (1 reinforcer of $0.03 \mathrm{~mL}$ per lever press) with $10 \%$ sucrose as the reinforcer and both levers active. Once rats had learned to respond for sucrose, they were water restricted and exposed to 45 min FR1 sessions for the next 5 d with a $10 \%$ sucrose solution as the reinforcer. The animals had free access to water in their home cages and received an additional $2 \mathrm{~d}$ training in accordance with the above protocol. After this initial training phase, the session time was shortened to $30 \mathrm{~min}$ and the response ratio was increased to 3 (FR3). At this point, a modified sucrose fade protocol was introduced with minor changes $^{[24-26]}$. Various sucrose solutions $(10 \%, 8 \%, 6 \%, 4 \%$, and $2 \%$ ) were blended with $5 \%$ ethanol and the rats received 3 training sessions for each mixture until they responded reliably under the FR3 schedule for 5\% ethanol alone and a second lever that delivered water was introduced. In the sucrose operant self-administration experiment, the sucrose concentration remained constant $(10 \%)$ and another lever delivered tap water. In all studies, the positions of the ethanol/sucrose solution and water were switched to prevent side bias.

As soon as stable lever pressing for ethanol/sucrose was established for at least 20 sessions, $\mathrm{FH} / \mathrm{Wjd}$ rats in both groups were divided into 4 subgroups $(n=5-6)$ that then received either a saline or BRU $(10,20$, and $30 \mathrm{mg} / \mathrm{kg}$, sc) treatment $2 \mathrm{~h}$ before each testing session.

\section{Ethanol deprivation test}

The ethanol intake of $\mathrm{FH} / \mathrm{Wjd}$ rats increases following an ethanol deprivation process ${ }^{[27,28]}$. A previous test found that the daily ethanol consumption of $\mathrm{FH} / \mathrm{Wjd}$ rats in a $10 \%$ ethanol group is higher than in a $5 \%$ ethanol group ${ }^{[22]}$. Thus, we studied the effects of BRU on deprivation-induced drinking in a group of $\mathrm{FH} / \mathrm{Wjd}$ rats that had been drinking $10 \%(v / v)$ ethanol voluntarily for at least 2 months. One group was tested for the baseline and the ethanol bottle of other 3 groups was removed from the cage for $5 \mathrm{~d}$. On the test day (at 8:00 $\mathrm{AM}$ and 7:30 PM), 4 groups $(n=6-9)$ of rats received a subcutaneous injection of $30 \mathrm{mg} / \mathrm{kg}$ BRU, saline or no treatment (2 groups). The ethanol bottle was replaced approximately 30 min prior to the beginning of the dark cycle (20:00 PM). Fluid consumption was recorded at 2, 4, 12, 24, 36, and $48 \mathrm{~h}$ after the ethanol bottle was replaced.

\section{Locomotor activity test}

Locomotor activity was measured in 4 chambers $(49 \mathrm{~cm} \times 49$ $\mathrm{cm} \times 59 \mathrm{~cm})$ situated in sound-attenuating cabinets $(96 \mathrm{~cm} \times 96$ $\mathrm{cm} \times 96 \mathrm{~cm}$ ) using Digbehv spontaneous activity monitors (DigBehv-LG, Shanghai Jiliang Software Technology Co Ltd, Shanghai, China ${ }^{[29]}$. The total distance of horizontal locomotor activity was recorded with a video camera located above the chamber and analyzed with the Digbehv software (Version 2.0, Shanghai Jiliang Software Technology Co Ltd, Shanghai,
China). The rats were divided into 4 groups $(n=6)$ matched for body weight. The rats received saline or BRU $(10,20$, and 30 $\mathrm{mg} / \mathrm{kg}, \mathrm{sc}$ ) and were then immediately put into the test chambers individually to measure their locomotion for $240 \mathrm{~min}^{[30]}$. Rats from the different experimental groups were tested in random order.

\section{Conditioned Place Preference (CPP) test}

The present study used an unbiased paradigm as described in previous studies ${ }^{[29,31,32]}$. $\mathrm{FH} / \mathrm{Wjd}$ rats were conditioned in the CPP apparatus, which consisted of three distinct chambers (two end-chambers of $28 \mathrm{~cm} \times 23 \mathrm{~cm} \times 20 \mathrm{~cm}, \mathrm{~L} \times \mathrm{W} \times \mathrm{H}$, and one middle chamber of $14 \mathrm{~cm} \times 23 \mathrm{~cm} \times 20 \mathrm{~cm}, \mathrm{~L} \times \mathrm{W} \times \mathrm{H}$ ) separated by a retractable guillotine door. The two end-chambers, defined as the conditioning chambers, were distinguishable by two somatosensory cues (tactile: stainless steel rod floor or stainless steel mesh floor; visual: radial or square shaping of five low-power red light bulbs). The movements of the animals through the apparatus were monitored by three infrared photocells ( $3 \mathrm{~cm}$ above floor) in each chamber, and the data were recorded using a computer. The CPP procedures included a 15-min pretest session (D 0; drug free), eight 45-min conditioning sessions (D 1 to D 8; drug or saline training), and a 15-min test session (D 9; drug free). On D 0, each rat was placed in the central compartment without the guillotine doors to allow free access to all three compartments. The amount of time spent in each compartment was recorded and used to assess the natural place preference tendency (exclusion criteria: time difference $>120$ s between the two end-compartments; attrition rate of $15 \%$ ). During the conditioning days, rats received saline or BRU $(10,20$, and $30 \mathrm{mg} / \mathrm{kg}, n=7-10)$ and were immediately confined to the saline-paired or drug-paired compartment for $45 \mathrm{~min}$. On test days, the rats were placed in the central compartment without an injection, and allowed to explore all three chambers freely for $15 \mathrm{~min}$. The CPP scores were calculated using the time (seconds) spent in the drugpaired compartment minus the time spent in the saline-paired side on the test days.

\section{Statistical analysis}

Data from the 2-bottle-choice test and locomotor activity test were analyzed using a two-factor repeated measures analysis of variance (RM-ANOVA). When three or more groups were compared, a one-way ANOVA was performed and, if significant, followed by post hoc analysis using the LSD tests. Statistical significance was considered to be $P<0.05$. The data shown are the mean \pm SEM.

\section{Results}

\section{Effects of BRU on ethanol intake in $\mathrm{FH} / \mathrm{Wjd}$ rats}

We first examined the effects of BRU on ethanol consumption in a 2-bottle free-choice drinking paradigm in $\mathrm{FH} / \mathrm{Wjd}$ rats, a strain that naturally drinks a large amount of ethanol ${ }^{[33]}$. During the first $3 \mathrm{~d}$ of saline administration, no significant difference was observed between the 4 groups [EtOH intake: $F(3,28)=0.215$, NS; water intake: $F(3,28)=1.731$, NS; total fluid 
intake: $F(3,28)=0.046$, NS; preference: $F(3,28)=1.426$, NS; food intake: $F(3,28)=0.668$, NS; body weight: $F(3,28)=0.056$, NS]. During the period of drug delivery, BRU (20 and 30 $\mathrm{mg} / \mathrm{kg}$ ) resulted in a significant reduction in daily ethanol intake, which persisted throughout the 10-d treatment period
$[F(3,28)=8.043, P<0.01]$ (Figure $2 \mathrm{~A})$. The reduction in daily ethanol intake of the BRU treatment groups was associated with a compensatory increase in water intake $[F(3,28)=6.305$, $P<0.01$ ] (Figure 2B), so that the daily total fluid intake $[F(3,28)=2.706, N S]$ remained unchanged (Figure $2 \mathrm{C}$ ), and the
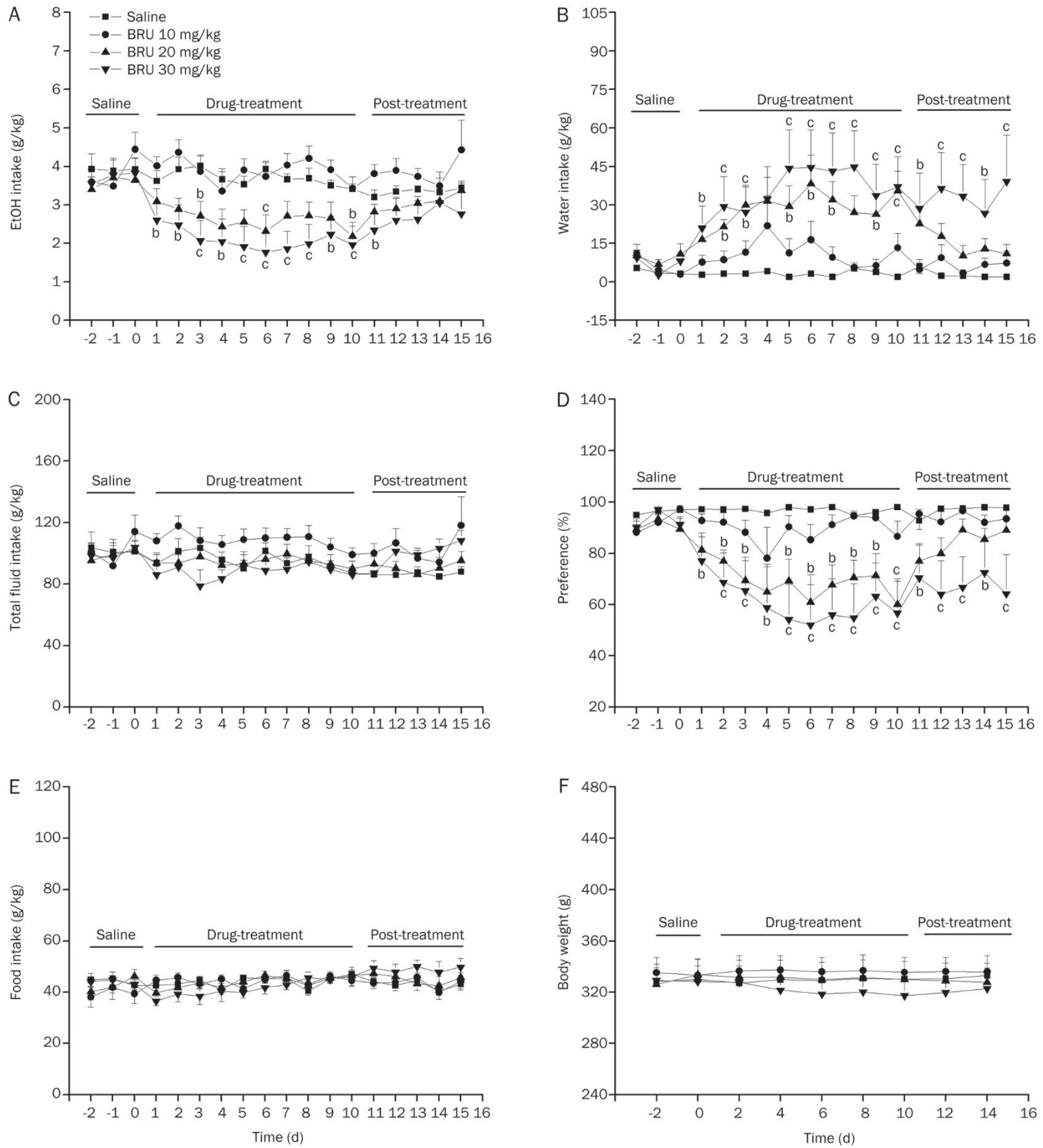

Figure 2. Effects of $B R U(10,20$, and $30 \mathrm{mg} / \mathrm{kg}$, sc, bid) on $\mathrm{EtOH}(5 \%, v / v)$ intake (A), water intake (B), total fluid intake (C), preference (D), food intake (E) and body weight $(F)$ in the ethanol 2-bottle-choice paradigm in $\mathrm{FH} / \mathrm{Wjd}$ rats. The experimental phases shown (from left to right) were the saline phase ( $\mathrm{d}$ $2-\mathrm{d} 0$ ), drug-treatment phase ( $\mathrm{d} 1-\mathrm{d} 10)$ and post-treatment phase ( $11-\mathrm{d} 15)$. The data are expressed as the mean \pm SEM $(n=8) .{ }^{b} P<0.05,{ }^{c} P<0.01$ versus the saline group. 
ethanol preference $[F(3,28)=6.824, P<0.01]$ (Figure 2D) was significantly decreased. Daily food intake $[F(3,28)=0.870, \mathrm{NS}]$ (Figure 2E) and body weight $[F(3,28)=0.332, \mathrm{NS}]$ (Figure 2F) were not significantly altered by drug treatment, suggesting that changes in ethanol intake were independent of food intake. During the post-treatment sessions, the ethanol intake $[F(3,28)=2.447, \mathrm{NS}]$ (Figure $2 \mathrm{~A})$ and preference $[F(3,28)=3.723$, $P<0.05$ ] (Figure 2D) of the BRU treated groups remained lower without a rebound increase.

\section{Effects of BRU on ethanol/sucrose self-administration in FH/Wjd} rats

In the ethanol operant self-administration paradigm, BRU reduced the number of lever presses for $5 \%$ ethanol in a doserelated manner compared to saline. Statistical significance was observed at the high dose $(30 \mathrm{mg} / \mathrm{kg})$ for the number of lever presses for ethanol $[F(3,18)=4.379, P<0.05)]$ (Figure 3A) and ethanol intake $[F(3,18)=3.794, P<0.05]$ (Figure 3B). The ethanol intake (in $\mathrm{mg} / \mathrm{kg}$, mean \pm SEM) for the saline, 10, 20,
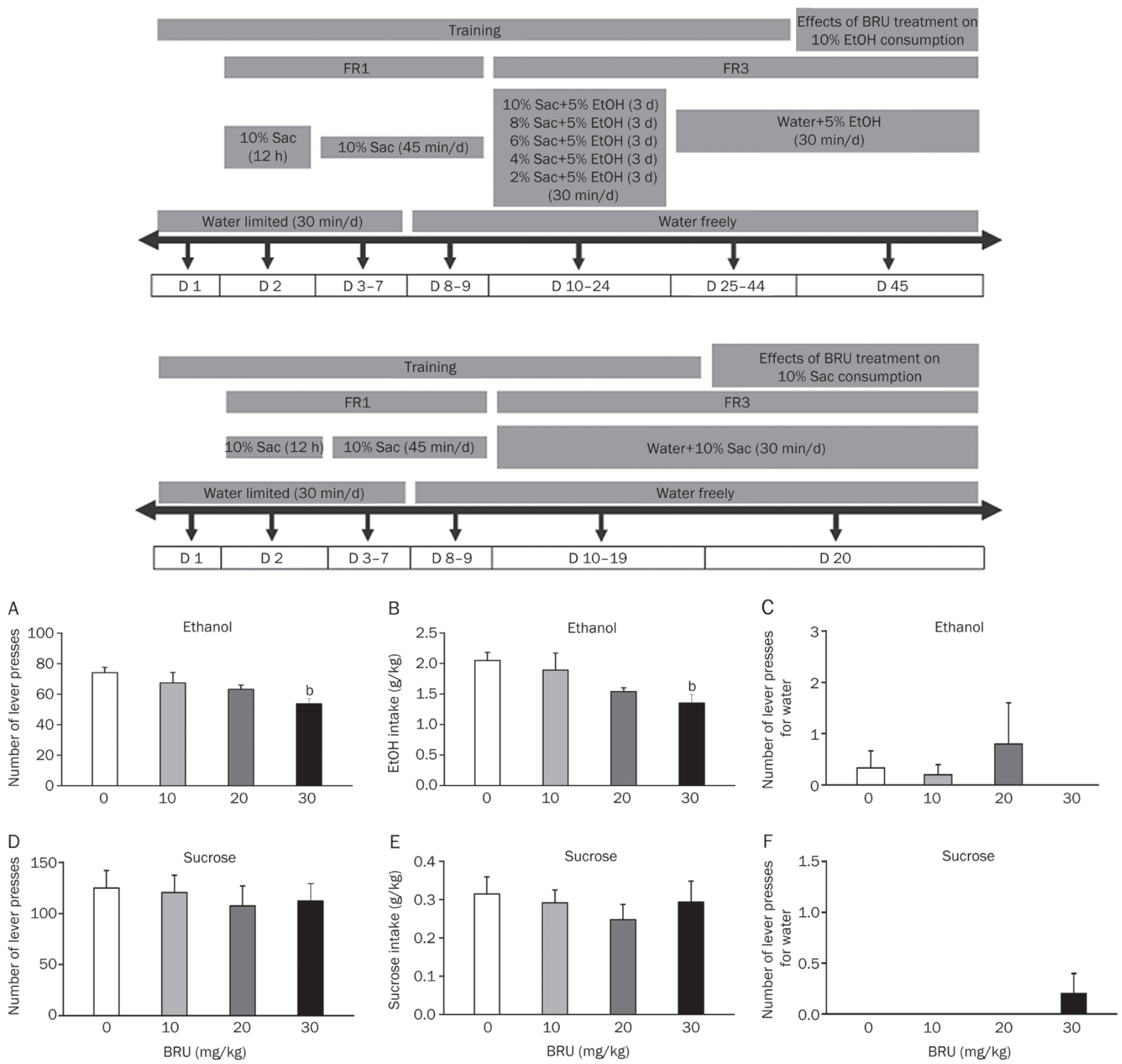

Figure 3. Effects of $\mathrm{BRU}(10,20$, and $30 \mathrm{mg} / \mathrm{kg}$, sc) on ethanol or sucrose self-administration during a $30 \mathrm{~min} F R 3$ session in FH/Wjd rats. The drug was administered (sc) $2 \mathrm{~h}$ before the beginning of the sessions. BRU (30 mg/kg) decreased the number of lever presses for ethanol (A) and the ethanol intake (B), but not the water responses (C). BRU did not decrease the number of lever presses for sucrose (D), sucrose intake (E) or the water responses (F) when sucrose was given. The number of lever presses for water in the $30 \mathrm{mg} / \mathrm{kg}$ BRU-treated group is zero (C). This is also the case for the saline-, 10and $20-\mathrm{mg} / \mathrm{kg}$ treated groups $(\mathrm{F})$. The data represent the mean \pm SEM $(n=5-6) .{ }^{\mathrm{b}} \mathrm{P}<0.05$ versus the saline group. 
and $30 \mathrm{mg} / \mathrm{kg}$ groups was $2.05 \pm 0.13,1.89 \pm 0.28,1.53 \pm 0.06$, and $1.35 \pm 0.14$, respectively. In contrast, all doses tested with BRU had no effect on the number of sucrose $(10 \%)$ responses $[F(3,17)=0.196, N S]$ (Figure 3D) or total sucrose intake $[F(3,17)=0.406, N S]$ (Figure 3E). Similarly, the number of lever presses for water were not significantly changed at any dose of BRU in both operant self-administration experiments (Figure $3 \mathrm{C}$ and $\mathrm{BF}$ ).

\section{$\mathrm{BRU}$ inhibited deprivation-induced drinking in $\mathrm{FH} / \mathrm{Wjd}$ rats}

Ethanol consumption of rats markedly increases after a period of abstinence, known as the ethanol deprivation effect ${ }^{[34]}$. The ethanol intake and preference were significantly increased between the baseline and untreated groups after a period of forced deprivation in heavy drinking $\mathrm{FH} / \mathrm{Wjd}$ rats (ethanol intake: at $2,4,12,24,36$, and $48 \mathrm{~h}, P<0.01, P<0.01, P<0.05$, $P<0.01, P<0.01$, and $P<0.01$, respectively; preference: NS, $P<0.05, P<0.01, P<0.01, P<0.01$, and $P<0.01$ at every time point; Figure 4). BRU abolished the increase in ethanol consumption observed in the saline group after the 5-d deprivation. A oneway ANOVA followed by a post hoc analysis revealed a significant difference between the $30 \mathrm{mg} / \mathrm{kg}$ BRU and saline groups on ethanol intake after $2,4,12,24,36$, and $48 \mathrm{~h}(P<0.01)$. Importantly, BRU continued to suppress deprivation-induced drinking and the preference to below baseline levels for the entire 48-h experiment (Figure 4). Total fluid intake was not affected by the BRU treatment over 24 or $48 \mathrm{~h}$ compared to the untreated and saline groups (data not shown).

\section{Effects of BRU on locomotor activity and CPP in $\mathrm{FH} / \mathrm{Wjd}$ rats}

A two-factor repeated measures ANOVA indicated that there were no differences between the groups in locomotor activity when the data were analyzed as 10 -min bins $\left[F_{\text {drug }}(3,20)=1.100\right.$, NS; $F_{\text {drug } \times \text { time }}(69,460)=0.743$, NS] (Figure 5$)$. The cumulative distances in $4 \mathrm{~h}$ were also statistically analyzed using a oneway ANOVA, and no statistical significance was found for BRU on the general locomotor activity $[F(3,20)=1.148$, NS $]$ (Figure 5 inset).

Neither group of treated rats exhibited a significant change in the time spent in the drug-paired compartment side $[F(3,28)=0.010, N S]$ (Figure 6). There was no evidence of conditioned place preference or aversion in $\mathrm{FH} / \mathrm{Wjd}$ rats when treated with BRU $(10,20$, and $30 \mathrm{mg} / \mathrm{kg})$ in the CPP paradigm. The average time (in $\mathrm{s}, \mathrm{mean} \pm \mathrm{SEM}$ ) in the drugpaired compartment for Sal-treated and BRU-paired (10, 20, and $30 \mathrm{mg} / \mathrm{kg}$ ) was $286.85 \pm 29.88,266.07 \pm 26.70,209.70 \pm 28.25$, and 297.04 \pm 25.81 , respectively. These data suggest that BRU does not appear to possess any intrinsic rewarding or aversive effects.

\section{Discussion}

Here, we show that BRU significantly suppressed voluntary ethanol intake and reduced ethanol preference as measured using the ethanol 2-bottle-choice drinking paradigm in alcohol-preferring $\mathrm{FH} / \mathrm{Wjd}$ rats. This effect was dose-related and apparent across the $10 \mathrm{~d}$ of drug treatment. The effect of
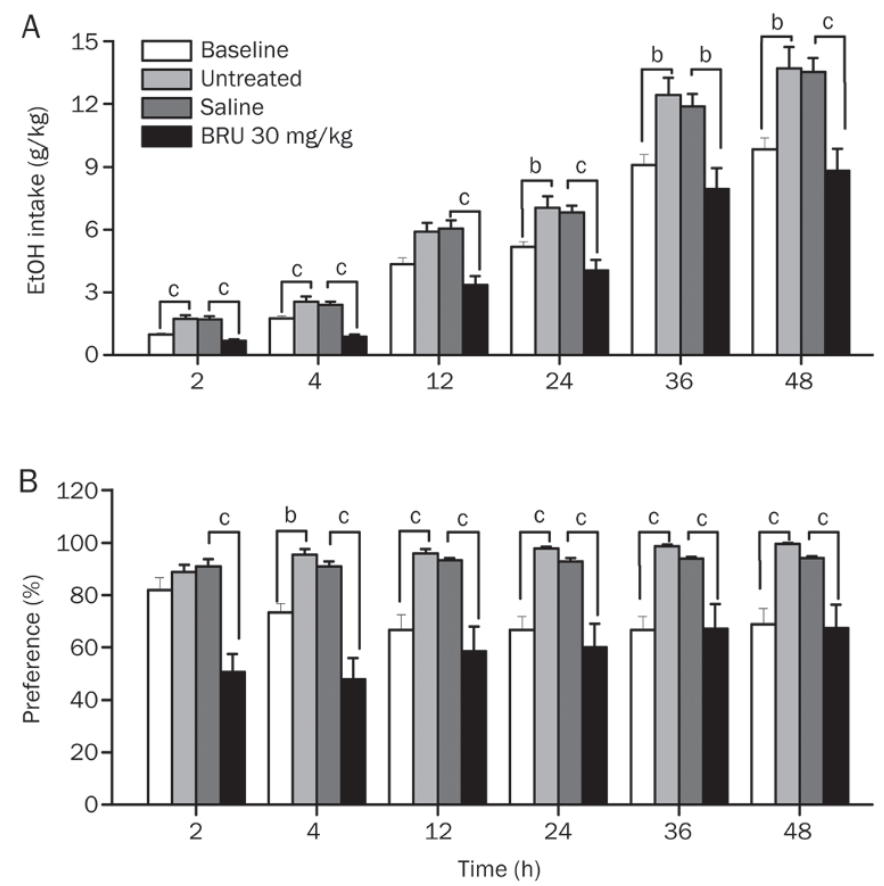

Figure 4. BRU (30 mg/kg, sc) attenuated ethanol consumption after being deprived of ethanol for $5 \mathrm{~d}$ in $\mathrm{FH} / \mathrm{Wjd}$ rats. Once the level of ethanol intake remained stable over 2 months, $\mathrm{FH} / \mathrm{Wjd}$ rats were tested for baseline or deprived of ethanol for $5 \mathrm{~d}$, and then the rats received a subcutaneous injection of BRU $30 \mathrm{mg} / \mathrm{kg}$, saline or no treatment. The ethanol intake and preference were determined over the following $48 \mathrm{~h}$. All data are expressed as the mean \pm SEM $(n=6-9) .{ }^{b} P<0.05,{ }^{c} P<0.01$ compared to the control group.

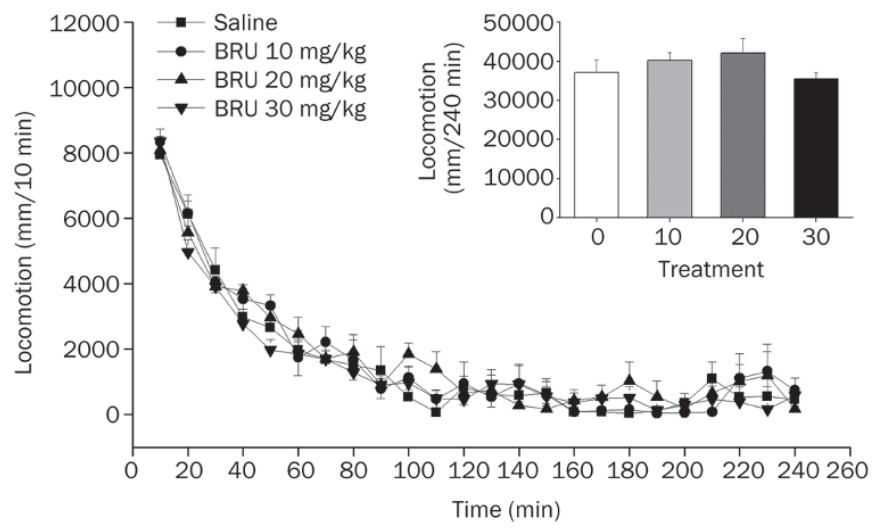

Figure 5. $\operatorname{BRU}(10,20$, and $30 \mathrm{mg} / \mathrm{kg}, \mathrm{sc})$ did not affect the locomotor activity in the open-field test in $\mathrm{FH} /$ Wjd Rats. Animals were injected with $\mathrm{BRU}$ or saline immediately before the test. Locomotion was recorded every $10 \mathrm{~min}$ for $4 \mathrm{~h}$. The data are expressed as the mean \pm SEM $(n=6)$.

BRU was selective for ethanol intake, as there was a compensatory increase in water intake and no consistent effects on total fluid intake. We also found that systemic administration of BRU $(30 \mathrm{mg} / \mathrm{kg})$ reduced ethanol operant self-administration but did not decrease sucrose or water self-administration. 


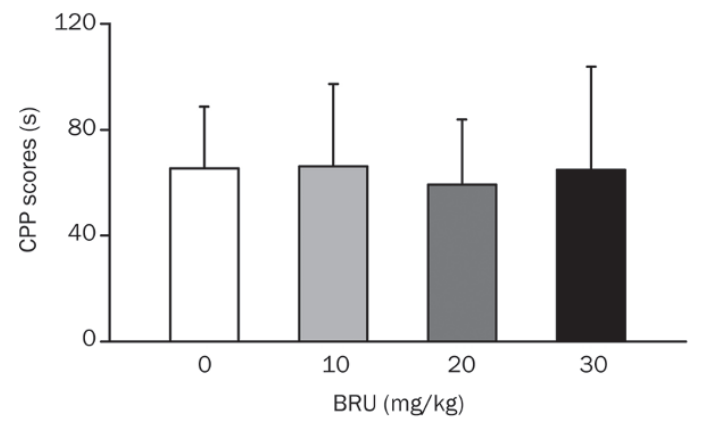

Figure 6. $\mathrm{BRU}(10,20$, and $30 \mathrm{mg} / \mathrm{kg}, \mathrm{sc})$ did not induce conditioned place preference or aversion in $\mathrm{FH} / \mathrm{Wjd}$ rats in an unbiased CPP test. Each point shows the mean \pm SEM $(n=7-10)$.

Naltrexone can cause an initial decrease in free-choice ethanol consumption by $\mathrm{FH} / \mathrm{Wjd}$ rats, but this effect diminished after a period of $7 \mathrm{~d}^{[35]}$. Tolerance also develops to acamprosate for voluntary ethanol intake and ethanol-seeking behaviors with repeated treatments ${ }^{[36]}$. The development of tolerance to the effects of these drugs in pre-clinical models has raised questions about their clinical utility ${ }^{[37]}$. In the course of a 10-d BRU treatment, no tolerance was observed. BRU has an elimination half-life $\left(T_{1 / 2}\right)$ of $2.9 \mathrm{~h}$ after transdermal administration $(40 \mathrm{mg} / \mathrm{kg})$ to ICR mice ${ }^{[13]}$. The inhibitory effect lasted for up to $5 \mathrm{~d}$ after subcutaneous injection in our study, suggesting that the duration of drug action is not tightly linked to the plasma concentration. The mechanisms underlying such a potent and long-lasting effect require further investigation. Nonetheless, this finding suggests that BRU may significantly decrease the frequency and volume of drinking in alcoholics ${ }^{[38]}$. In addition, taste preference may influence ethanol consumption. In the sucrose self-administration test, the development of preference for sucrose solution was not changed, suggesting that BRU does not decrease the taste of natural rewards.

Relapse to heavy ethanol drinking after a period of abstinence is a serious problem in the treatment of human alcoholism $^{[27]}$. The ethanol deprivation effect, raised first in 1967 by Sinclair and Senter, appears to be an index of craving for ethanol ${ }^{[39,40]}$. The time course of $\mathrm{FH} / \mathrm{Wjd}$ rats on $10 \%$ ethanol consumption for $2,4,6,12$, and $24 \mathrm{~h}$ has been reported ${ }^{[27,28]}$. In the present study, we found that the ethanol intake of $\mathrm{FH} / \mathrm{Wjd}$ rats was similar to the previous studies at every time point and had the tendency to increase after $5 \mathrm{~d}$ of ethanol deprivation. BRU ( $30 \mathrm{mg} / \mathrm{kg}$, sc, bid) reduced ethanol intake and preference after a 5 -d deprivation in rats over a $48 \mathrm{~h}$ period. Thus, if these finding can be translated clinically, BRU may reduce the relapse rate and prolong abstinence in alcoholic patients.

The place-conditioning paradigm is widely used to assess the rewarding or aversive properties of $\mathrm{drugs}^{[41]}$. BRU at behaviorally effective doses (20 and $30 \mathrm{mg} / \mathrm{kg}$ ) displayed no rewarding or aversive effects in the CPP test. In addition, BRU did not alter the general locomotor activity of the rats suggesting that BRU is not a general CNS depressant. Moreover, BRU did not alter sucrose drinking behavior. Together, these data strongly suggest that BRU decreases ethanol drinking and ethanol preference via specific neurobiological mechanisms but not via non-specific behavioral suppression or drug-induced taste aversion. Pharmacokinetic studies following dermal administration show that liposomal BRU distributes widely and could be detected in the liver, heart, spleen, lung, kidney, brain and muscle tissues ${ }^{[15]}$. BRU can also pass the blood brain barrier and reach stable drug levels in the mouse brain ${ }^{[13]}$. BRU is also believed to produce anti-nociceptive effects in a hot-plate test through central mechanisms ${ }^{[12]}$. In view of the above, it is likely that BRU may exert its inhibitory actions on ethanol drinking in the central nervous system.

Electrophysiological studies show that ethanol can enhance glycine receptor function in mouse and chick embryonic spinal neurons in a concentration-dependent manner ${ }^{[42]}$. Meanwhile, Mascia et al found that ethanol could potentiate homomeric a1 or a2 glycine receptors expressed in Xenopus oocytes $^{[19]}$. Ethanol has its enhancing effects on glycine receptor function mainly by increasing burst durations ${ }^{[43]}$. The basic mechanism of alcohol appears to be its antagonism of glycine unbinding from the glycine receptors ${ }^{[43]}$. Ethanol can increase glycine-mediated chloride uptake into rat brain synaptoneurosomes ${ }^{[4]}$. Work by Jonsson et al found that a 1 subunit expression in the nucleus accumbens is related to ethanol intake in ALKO Alcohol (AA) rats ${ }^{[45]}$. Microinjection of glycine into the ventral tegmental area selectively decreases ethanol consumption in rats ${ }^{[46]}$. However, there is currently no report showing a synthetic glycine receptor ligand can specifically decrease ethanol consumption. BRU acts as an antagonist at the $\mathrm{a} 1$ and a1 $\beta$ glycine receptors in human embryonic kidney 293 cells with $K_{\mathrm{i}}$ values $(\mu \mathrm{mol} / \mathrm{L})$ of 1.7 and 1.4 , respectively ${ }^{[20]}$. Therefore, it is possible that ethanol and BRU modulate behavior via opposing actions on the glycine receptors of rats. If so, then glycine receptors could be an interesting drug target for the treatment of alcoholism ${ }^{[46]}$. Bilateral accumbal microinjection of glycine enhances the DA-activating effects of ethanol, thus decreasing ethanol self-administration in Wistar rats ${ }^{[47]}$. Given the complexity of the neural circuitry that participates in the control of alcohol reinforcement, it may not be surprising that systemic versus targeted injection of glycine receptor ligands produce inconsistent behavioral effects, and thus further highlight the complicated role of glycine receptors in alcohol use. BRU also binds to serotonin $5-\mathrm{HT}_{3}$ receptors with a $K_{\mathrm{i}}$ value of $6.2 \mu \mathrm{mol}^{[20]}$. It is well known that $5-\mathrm{HT}_{3}$ receptor antagonists such as ondansetron, block alcohol stimulated DA release in the mesolimbic system and attenuate ethanol consumption during acquisition, maintenance and deprivation in male $\mathrm{P}$ rats $^{[48]}$. Studies demonstrate that antimuscarinic agents induce a comparable decrease in alcohol intake in $\mathrm{FH} / \mathrm{Wjd}$ and $\mathrm{P}$ rat $^{[49]}$. BRU is also an allosteric modulator of muscarinic acetylcholine receptors ${ }^{[50]}$. Thus, $5-\mathrm{HT}_{3}$ and muscarinic receptor antagonism could be two other potential mechanisms that may mediate the pharmacological effects of BRU observed in the current study.

In conclusion, this study found that BRU exerts marked and specific effects, reducing ethanol drinking and preference 
behaviors in a strain of alcohol-preferring rats, with little evidence for the development of tolerance. BRU has a good safety profile in preliminary toxicology studies. Because alcohol abuse and alcoholism remain significant psychiatric disorders that can be resistant to current treatments, these preclinical findings encourage further examination of BRU for treating alcohol use disorders.

\section{Acknowledgements}

This study was supported by the National Natural Science Foundation of China (30870894 and 81373390); National Basic Research Program of China (2009CB522000); National Key Technology R\&D Program of China (2011BAK04B08); and Key Research Items of Ministry of Public Security (2009ZDYJHLJT003). Jian-hui LIANG was supported by the National Institute on Drug Abuse at the National Institutes of Health under awards (R01DA034806 and R21DA033426). Andrew J LAWRENCE is a Principal Research Fellow at the NHMRC, Australia, and was supported by the Victorian Government's Operational Infrastructure Support Scheme.

\section{Author contribution}

Yu-ling LI, Jian-hui LIANG, and Andrew J LAWRENCE contributed to the research design; Yu-ling LI, Qing LIU, Qi GONG, Shou-peng WEI, Yan-ting WANG, Hui LIANG, Min ZHANG, and Li JING performed the experiments; Yu-ling LI and Jian-hui LIANG performed the data analysis; Yu-ling LI, Jun-xu LI, Zheng YONG, Andrew J LAWRENCE, and Jian-hui LIANG wrote or contributed to the writing of the manuscript.

\section{References}

1 Jupp B, Lawrence AJ. New horizons for therapeutics in drug and alcohol abuse. Pharmacol Ther 2010; 125: 138-68.

2 Liu Q, Lawrence AJ, Liang JH. Traditional Chinese medicine for treatment of alcoholism: from ancient to modern. Am J Chin Med 2011; 39: 1-13.

3 Baan R, Straif K, Grosse Y, Secretan B, El Ghissassi F, Bouvard V, et al. Carcinogenicity of alcoholic beverages. Lancet Oncol 2007; 8: 292-3.

4 Roerecke M, Rehm J. Ischemic heart disease mortality and morbidity rates in former drinkers: a meta-analysis. Am J Epidemiol 2011; 173: 245-58.

5 Samokhvalov AV, Irving H, Mohapatra S, Rehm J. Alcohol consumption, unprovoked seizures, and epilepsy: a systematic review and meta-analysis. Epilepsia 2010; 51: 1177-84.

6 Spicak J, Pulkertova A, Kralova-Lesna I, Suchanek P, Vitaskova M, Adamkova V. Alcoholic chronic pancreatitis and liver cirrhosis: coincidence and differences in lifestyle. Pancreatology 2012; 12: 311-6.

7 Krampe H, Stawicki S, Wagner T, Bartels C, Aust C, Rüther E, et al. Follow-up of 180 alcoholic patients for up to 7 years after outpatient treatment: impact of alcohol deterrents on outcome. Alcohol Clin Exp Res 2006; 30: 86-95.

8 Kampman KM, Pettinati HM, Lynch KG, Xie H, Dackis C, Oslin DW, et al. Initiating acamprosate within-detoxification versus postdetoxification in the treatment of alcohol dependence. Addict Behav 2009; 34: 581-6.

9 O'Brien CP, Volpicelli LA, Volpicelli JR. Naltrexone in the treatment of alcoholism: a clinical review. Alcohol 1996; 13: 35-9.

10 Rösner S, Hackl-Herrwerth A, Leucht S, Vecchi S, Srisurapanont M, Soyka M. Opioid antagonists for alcohol dependence. Cochrane Database Syst Rev 2010; (12): CD001867.

11 Heilig M, Egli M. Pharmacological treatment of alcohol dependence: target symptoms and target mechanisms. Pharmacol Ther 2006; 111: 855-76.

12 Yin W, Wang TS, Yin FZ, Cai BC. Analgesic and anti-inflammatory properties of brucine and brucine $\mathrm{N}$-oxide extracted from seeds of Strychnos nux-vomica. J Ethnopharmacol 2003; 88: 205-14.

13 Chen J, Hu W, Qu YQ, Dong J, Gu W, Gao Y, et al. Evaluation of the pharmacodynamics and pharmacokinetics of brucine following transdermal administration. Fitoterapia 2013; 86: 193-201.

14 Deng XK, Yin W, Li WD, Yin FZ, Lu XY, Zhang XC, et al. The anti-tumor effects of alkaloids from the seeds of Strychnos nux-vomica on HepG2 cells and its possible mechanism. J Ethnopharmacol 2006; 106: 179-86.

15 Yang BC, Chu ZF, Zhu S, Wang LJ, Feng YH, Li FH, et al. Study of pharmacokinetics and tissue distribution of liposomal brucine for dermal administration. Int J Nanomed 2011; 6: 1109-16.

16 Chen J, Hou T, Fang Y, Chen ZP, Liu X, Cai H, et al. HPLC determination of strychnine and brucine in rat tissues and the distribution study of processed semen strychni. Yakugaku Zasshi 2011; 131: 721-9.

17 Dhalwal K, Shinde VM, Namdeo AG, Mahadik KR, Kadam SS. Development and validation of a TLC-densitometric method for the simultaneous quantitation of strychnine and brucine from Strychnos spp. and its formulations. J Chromatogr Sci 2007; 45: 706-9.

18 Mihic SJ, Ye Q, Wick MJ, Koltchine VV, Krasowski MD, Finn SE, et al. Sites of alcohol and volatile anaesthetic action on $\mathrm{GABA}_{\mathrm{A}}$ and glycine receptors. Nature 1997; 389: 385-9.

19 Mascia MP, Machu TK, Harris RA. Enhancement of homomeric glycine receptor function by long-chain alcohols and anaesthetics. $\mathrm{Br}$ J Pharmacol 1996; 119: 1331-6.

20 Jensen AA, Gharagozloo P, Birdsall NJ, Zlotos DP. Pharmacological characterisation of strychnine and brucine analogues at glycine and alpha7 nicotinic acetylcholine receptors. Eur J Pharmacol 2006; 539: 27-33.

21 Overstreet DH, McArthur RA, Rezvani AH, Post C. Selective inhibition of alcohol intake in diverse alcohol-preferring rat strains by the $5-\mathrm{HT}_{2 \mathrm{~A}}$ antagonists amperozide and FG 5974. Alcohol Clin Exp Res 1997; 21: 1448-54.

22 Jing L, Zhang ZH, Wang WP, Zhang M, Luo J, Chen F, et al. Characteristics of alcohol-preferring behavior in $\mathrm{FH} / \mathrm{Wjd}$ rats. Chin $\mathrm{J}$ Pharmacol Toxicol 2009; 23: 65-9.

23 Wen RT, Zhang M, Qin WJ, Liu Q, Wang WP, Lawrence AJ, et al. The phosphodiesterase-4 (PDE4) inhibitor rolipram decreases ethanol seeking and consumption in alcohol-preferring Fawn-Hooded rats. Alcohol Clin Exp Res 2012; 36: 2157-67.

24 Samson $\mathrm{HH}$. Initiation of ethanol reinforcement using a sucrosesubstitution procedure in food- and water-sated rats. Alcohol Clin Exp Res 1986; 10: 436-42.

25 Steensland P, Simms JA, Holgate J, Richards JK, Bartlett SE. Varenicline, an alpha4beta2 nicotinic acetylcholine receptor partial agonist, selectively decreases ethanol consumption and seeking. Proc Natl Acad Sci U S A 2007; 104: 12518-23.

26 Arolfo MP, Yao L, Gordon AS, Diamond I, Janak PH. Ethanol operant self-administration in rats is regulated by adenosine $A_{2}$ receptors. Alcohol Clin Exp Res 2004; 28: 1308-16.

27 Rezvani AH, Parsian A, Overstreet DH. The Fawn-Hooded (FH/Wjd) rat: a genetic animal model of comorbid depression and alcoholism. Psychiatr Genet 2002; 12: 1-16. 
28 Arolfo MP, Overstreet DH, Yao L, Fan P, Lawrence AJ, Tao G, et al. Suppression of heavy drinking and alcohol seeking by a selective ALDH-2 inhibitor. Alcohol Clin Exp Res 2009; 33: 1935-44.

29 Liu Q, Zhang M, Qin WJ, Wang YT, Li YL, Jing L, et al. Septal nuclei critically mediate the development of behavioral sensitization to a single morphine injection in rats. Brain Res 2012; 1454: 90-9.

$30 \mathrm{Hu}$ W, Lu T, Chen A, Huang Y, Hansen R, Chandler $\sqcup$, et al. Inhibition of phosphodiesterase-4 decreases ethanol intake in mice. Psychopharmacology (Berl) 2011; 218: 331-9.

31 Zhang M, Jing L, Liu Q, Wen RT, Li JX, Li YL, et al. Tramadol induces conditioned place preference in rats: interactions with morphine and buprenorphine. Neurosci Lett 2012; 520: 87-91.

32 dela Cruz AM, Herin DV, Grady JJ, Cunningham KA. Novel approach to data analysis in cocaine-conditioned place preference. Behav Pharmacol 2009; 20: 720-30.

33 Rezvani AH, Overstreet DH, Janowsky DS. Genetic serotonin deficiency and alcohol preference in the fawn hooded rats. Alcohol Alcohol 1990; 25: 573-5.

34 Rodd ZA, Bell RL, Sable HJ, Murphy JM, McBride WJ. Recent advances in animal models of alcohol craving and relapse. Pharmacol Biochem Behav 2004; 79: 439-50.

35 Cowen MS, Rezvani AH, Jarrott B, Lawrence AJ. Ethanol consumption by Fawn-Hooded rats following abstinence: effect of naltrexone and changes in mu-opioid receptor density. Alcohol Clin Exp Res 1999; 23: $1008-14$

36 Cowen MS, Adams C, Kraehenbuehl T, Vengeliene V, Lawrence AJ. The acute anti-craving effect of acamprosate in alcohol-preferring rats is associated with modulation of the mesolimbic dopamine system. Addict Biol 2005; 10: 233-42.

37 Overstreet DH, Rezvani AH, Djouma E, Parsian A, Lawrence AJ. Depressive-like behavior and high alcohol drinking co-occur in the FH/WJD rat but appear to be under independent genetic control. Neurosci Biobehav Rev 2007; 31: 103-14.

38 Carroll ME, Morgan AD, Anker JJ, Perry JL, Dess NK. Selective breeding for differential saccharin intake as an animal model of drug abuse. Behav Pharmacol 2008; 19: 435-60.

39 McBride WJ, Le AD, Noronha A. Central nervous system mechanisms in alcohol relapse. Alcohol Clin Exp Res 2002; 26: 280-6.

40 Spanagel R, Hölter SM, Allingham K, Landgraf R, Zieglgänsberger W. Acamprosate and alcohol: I. Effects on alcohol intake following alcohol deprivation in the rat. Eur J Pharmacol 1996; 305: 39-44.

41 Mucha RF, Iversen SD. Reinforcing properties of morphine and naloxone revealed by conditioned place preferences: a procedural examination. Psychopharmacology (Berl) 1984; 82: 241-7.

42 Aguayo LG, Pancetti FC. Ethanol modulation of the gammaaminobutyric acidA- and glycine-activated $\mathrm{Cl}^{-}$current in cultured mouse neurons. J Pharmacol Exp Ther 1994; 270: 61-9.

43 Welsh BT, Goldstein BE, Mihic SJ. Single-channel analysis of ethanol enhancement of glycine receptor function. J Pharmacol Exp Ther 2009; 330: 198-205.

44 Engblom AC, Akerman KE. Effect of ethanol on gamma-aminobutyric acid and glycine receptor-coupled $\mathrm{Cl}^{-}$fluxes in rat brain synaptoneurosomes. J Neurochem 1991; 57: 384-90.

45 Jonsson S, Kerekes N, Hyytiä P, Ericson M, Söderpalm B. Glycine receptor expression in the forebrain of male AA/ANA rats. Brain Res 2009; 1305: S27-36.

46 Li J, Nie H, Bian W, Dave V, Janak PH, Ye JH. Microinjection of glycine into the ventral tegmental area selectively decreases ethanol consumption. J Pharmacol Exp Ther 2012; 341: 196-204.

47 Molander A, Löf E, Stomberg R, Ericson M, Söderpalm B. Involvement of accumbal glycine receptors in the regulation of voluntary ethanol intake in the rat. Alcohol Clin Exp Res 2005; 29: 38-45.

48 Rodd-Henricks ZA, McKinzie DL, Edmundson VE, Dagon CL, Murphy $\mathrm{JM}, \mathrm{McBride}$ WJ, et al. Effects of $5-\mathrm{HT}_{3}$ receptor antagonists on daily alcohol intake under acquisition, maintenance, and relapse conditions in alcohol-preferring (P) rats. Alcohol 2000; 21: 73-85.

49 Rezvani AH, Overstreet DH, Janowsky DS. Drug-induced reductions in ethanol intake in alcohol preferring and Fawn-Hooded rats. Alcohol Alcohol Suppl 1991; 1: 433-7.

50 Zlotos DP, Buller S, Stiefl N, Baumann K, Mohr K. Probing the pharmacophore for allosteric ligands of muscarinic $M 2$ receptors: SAR and QSAR studies in a series of bisquaternary salts of caracurine $V$ and related ring systems. J Med Chem 2004; 47: 3561-71. 